\title{
Noisy Days, Noisy Nights
}

\section{David Sharp}

Noise as an ambient pollutant was for a long time neglected, at least when set beside air or water pollution. Several reasons for this neglect come to mind. The only definition of noise that we have is "unwanted sound," but that is highly subjective; to some, a full-blooded performance of Shostakovich's 10th symphony is a pleasure, to others cacophony. Also, sound is hard to measure. The bel was not adopted as a base unit by the Système International, and one scholarly explanation of the complexities of the widely used decibel illustrates the difficulties. ${ }^{1}$ The human impact of unwanted sound shades from mere annoyance to disturbed sleep, stress, hearing damage, hypertension, and even ischemic heart disease, but the strength of the evidence varies, as do the settings, which range from exposure at the workplace, living close to busy roads, or being close to an airport, to just having noisy neighbors. Noise is not exclusively an urban problem, but high population density and heavily used transport systems do not make for a quiet life in cities, and much of today's reawakened interest in "noise and health" (a quarterly journal of that name began life in 1998) relates to the results of urban studies of noise from road vehicles and aircraft.

Anne Vernez Moudon from the University of Washington, Seattle, has an academic remit that covers, unusually and maybe even uniquely, architecture, urban design, environmental engineering, and epidemiology. Her 2009 review concludes that it is time to reverse the neglect of health and the acoustic environment. ${ }^{2}$ Noise can be tackled at source by the development of less noisy engines and at one remove via quieter road surfaces, and such changes would be encouraged by the tightening of noise thresholds. The latter is something that the World Health Organization pronounced upon a decade ago. ${ }^{3}$ WHO's European regional office has recently built on that 1999 report, this time focusing on nocturnal exposure. ${ }^{4}$ The evidence up to 2006 (which was when the European WHO experts drafted their opinion) suggested a broad dose-response. At exposures averaging less than $30 \mathrm{~dB}(\mathrm{~A})$, the suffix $(\mathrm{A})$ meaning that the meter is focusing on frequencies in the range the human ear is especially sensitive to, there are no substantial biological effects; in the 30-40 dB(A) range, effects are at worst only modest; adverse effects can be seen at $40-55 \mathrm{~dB}(\mathrm{~A})$; and increasing risks to health are seen above $55 \mathrm{db}(\mathrm{A})$. From $130 \mathrm{~dB}(\mathrm{~A})$ or so, noise is acutely painful.

The notion of a dose-response relationship between noise and more specific health outcomes has been gaining support for some years now, from studies small and large and with the occasional meta-analysis. When Babisch reviewed the cardiovascular evidence in 2006, he found it stronger than it had been 6 years earlier. ${ }^{5}$ Moudon feels that it is time for this dose-response to be "translated into epidemiologic terms measuring population-wide effects." ${ }^{2}$ The title of the 2008

\footnotetext{
Correspondence: David Sharp, 2 Iron Mills, Minchinhampton, GL6 9AL, UK. (E-mail: davidwsharp @sky.com)

Sharp is a freelance writer in Minchinhampton, UK.
} 
International Congress on Biological Effects of Noise in the Environment, which was "Noise as a Public Health Problem," implies that, to some, this translation is already happening. Evaluations in the UK are starting to look at the public health impact of noise in economic terms; one rough estimate puts the cost to the economy at $£ 7$ billion annually. ${ }^{6}$

Annoyance is very subjective. Occupational noise-induced hearing loss is well recognized and widely regulated, perhaps not always with the hoped-for improvements, as a recent New Zealand study suggests. ${ }^{7}$ Those seeking evidence for noise's effects on illnesses other than hearing loss (and annoyance) have access to several recent reviews. ${ }^{2,4,8-10}$ Examples of the newer findings include a study in which the building of a bypass affecting three small towns in north Wales, UK, provided an opportunity for a before-and-after comparison of groups exposed to high and low noise levels. ${ }^{11}$ The absence of a difference in annoyance ratings and mental disorder at baseline limits the conclusions that can be drawn other than to say that achieving noise reductions of the order of only $2-4 \mathrm{~dB}(\mathrm{~A})$ is unlikely to have much effect. However, more intervention studies would be welcome. A German investigation of children aged 8-14 years compared those who did not sleep facing a street with children exposed to noise from high traffic volumes. Blood pressure rose by 1.0/ $0.66 \mathrm{mmHg}$ for every $1 \mathrm{~dB}(\mathrm{~A})$ increase in noise. ${ }^{12}$ Jarup et al. found that $10 \mathrm{~dB}$ increments in air and road traffic noise were associated with small but significant increments in hypertension risk. ${ }^{13}$

If the epidemiological evidence is indeed increasingly pointing to some sort of dose-related link between noise and potentially serious ill-health what might the biological mechanism be? In the UK, it is estimated that half the population live in areas where daytime noise levels exceed WHO-recommended ceilings, and at nighttime, the proportion rises to two thirds. Yet, the impact (power) of the $57 \mathrm{~dB}(\mathrm{~A}$ ) mean UK noise level during the day is tiny, half a microwatt per square meter. ${ }^{10}$ Causation via some direct biophysical route seems highly unlikely, and the current working hypothesis is stress and its hormonal consequences. Ambient noise deserves at least as much attention from cortisol and catecholamine physiology as it has lately been getting from epidemiology.

\section{REFERENCES}

1. University of New South Wales School of Physics. dB: what is a decibel? http://www.phys. unsw.edu.au/jw/dB.html. Accessed November 10, 2009.

2. Mouzon AV. Real noise from urban environments: how low ambient community noise affects health and what can be done about it. Am J Prev Med. 2009; 37: 167-171.

3. Berglund B, Lindvall T, Schwela DH, eds. Guidelines for community noise. Geneva: World Health Organization; 1999. http://www.who.int/docstore/peh/noise/guidelies2. html. Accessed November 16, 2009.

4. WHO Regional Office for Europe. Night noise guidelines for Europe. Copenhagen; World Health Organization; 2009. http://www.euro.who.int/Document/E92845.pdf. Accessed November 10, 2009.

5. Babisch W. Transportation noise and cardiovascular risk: updated review and synthesis of epidemiological studies indicating that the evidence has increased since 2000. Noise Health. 2006; 8: 1-29.

6. Berry BF, Flindell IH. Estimating dose-response relationships between noise exposure and human health in the UK: executive summary. http://www.defra.gov.uk/environment/ quality/noise/igeb/documents/executive-summary.pdf. Accessed November 16, 2009. 
7. Thorne PR, Ameratunga SN, Stewart J, et al. Epidemiology of noise-induced hearing loss in New Zealand. NZ Med J. 2008; 121: 33-44.

8. Babisch W, Kamp I. Exposure-response relationship of the association between aircraft noise and the risk of hypertension. Noise Health. 2009; 11: 161-168.

9. Stansfeld SA, Matheson MP. Noise pollution: non-auditory effects on health. Br Med Bull. 2003; 68: 243-257.

10. Health Protection Agency. Environmental noise and health in the UK. London, Health Protection Agency, 2009. http://www.hpa.org.uk/web/HPAwebFile/HPAweb_C/ 1246433634856. Accessed November 16, 2009.

11. Stansfeld SA, Haines MM, Berry B, Burr M. Reduction in road traffic noise and mental health: an intervention study. Noise Health. 2009; 11: 169-175.

12. Babisch W, Neuhauser H, Thamm M, Seiwert M. Blood pressure of 8014 year old children in relation to traffic noise at home. Sci Total Environ. 2009; 5: 839-843.

13. Jarup L, Babisch W, Houthuijs D, et al. Hypertension and exposure to noise near airports: the HYENA Study. Environ Health Perspect. 2008; 116: 329-333. 